\title{
Techniques de production de plants de merisier (Prunus avium L.) par culture in vitro Bouturage herbacé, bouturage de racines
}

\author{
Catherine CHAIX \\ I.N.R.A. Station d'Amélioration des Arbres forestiers \\ Centre de Recherches d'Orléans-Ardon - F 45160 Olivet
}

Dans le cadre de l'amélioration génétique du merisier (Prunus avium L.) on a expérimenté trois techniques de multiplication végétative en masse : culture in vitro, bouturage de racines, bouturage herbacé.

\section{Culture in vitro}

Elle passe par quatre phases successives : initiation, multiplication, élongation, enracinement.

La culture de méristèmes, prélevés dans des bourgeons d'arbres adultes en arrêt de croissance, comporte moins de risques d'infections (fongiques ou bactériennes) que la culture à partir de bourgeons entiers ou de drageons. Les pousses axillaires formées sont installées sur milieu de multiplication (1), chacune produisant deux à huit nouvelles pousses axillaires, selon le clone. Placés en chambre froide (à 2 "C) les explants peuvent se conserver plusieurs mois; après six mois ils se multiplient très vigoureusement. Une diminution de la concentration en B.A. $\left(2.10^{-6} \mathrm{M}\right)$ permet de corriger le phénomène de transformation hyperhydrique qui affecte certains clones. On peut obtenir des pousses allongées utilisables directement en enracinement

(1) Milieu de base : macroéléments et microéléments de Murashige et Skoog dont la concentration en $\mathrm{NH}_{4} \mathrm{NO}_{3}$ est diminuée de moitié et celle de Fe et $\mathrm{S}$ doublée, mélange vitaminique, myoinositol, L-glutamine, saccharose $20 \mathrm{~g} / 1$, agar $7 \mathrm{~g} / 1$, régulateurs de croissance : acide indolbutyrique (AIB) : $5 \cdot 10^{-6} \mathrm{M}$, benzylaminopurine (BA) $: 4 \cdot 10^{-8} \mathrm{M}$, acide gibberellique (AG) $: 3.10^{-7} \mathrm{M}$. 
en augmentant la concentration en $\mathrm{AG}\left(3.10^{-6} \mathrm{M}\right)$ et en diminuant conjointement celle en B.A. $\left(2.10^{-6} \mathrm{M}\right)$.

Le milieu d'enracinement ${ }^{2}{ }^{2}$ permet, pour deux tiers des clones, d'obtenir plus de $60 \%$ de plants enracinés. Pour les clones manifestant une faible aptitude à l'enracinement, on multiplie par dix la concentration en AIB. Des conditions de faible température et luminosité $\left(20^{\circ} \mathrm{C}-500 \mathrm{Lux}\right)$ sont indispensables à l"enracinement, pour tous les clones. Après trois à cinq semaines, les plants enracinćs sont repiqués sur terreau en enceinte climatisée, la survie est voisine de $80 \%$.

En pratique, on a pu programmer une multiplication massale de clones au cours de l'automne et de l'hiver. Le matériel multiplié et stocké en chamtre froide subit un traitement destiné à favoriser au printemps l'élongation puis l'enracınemcni.

\section{Bouturage de racines}

La formation d'un drageon à l'extrémité proximale, puis de nouvelles racines à l'extrémité distale est conditionnée par une dimension suffisamment importante de la bouture de racine $(20 \mathrm{~cm}$ de long environ). La faible production de ce type de bouture par plant conduirait à l'exploitation d'une partie des plants à installer en plantation.

\section{Bouturage herbacé}

Les essais ont eu lieu en avril, à partir de copies végétatives de un an des arbres sélectionnés, élevées en serre. On sectionne les rameaux herbacés en boutures de un nœud ; la présence de la feuille est indispensable à la survie des boutures. L'enceinte de bouturage est confinée et munie d'un chauffage de fond et d'une brumisation intermittente. Le substrat est un mélange de perlite et de terreau.

On a étudié l'influence d'un traitement auxinique sur quatorze clones, par poudrage de la base des boutures avec de l'AIB (à $0,1 \%-0,5 \%-1 \%$ ). Avec l'AIB à $0,5 \%, 85 \%$ des boutures s'enracinent vigoureusement en quatre semaines. Seul un des clones manifeste une faible aptitude au bouturage ( $25 \%$ d'enracinement). Avec l'AIB à $0,1 \%$ et $1 \%$ et sans $\mathrm{AIB}$, l'enracinement est moins fréquent et plus lent, on observe souvent la formation de cals.

Toutes les boutures dont le bourgeon a débourré avant le bouturage (phénomène observé sur cinq clones) s'enracinent rapidement, sans traitement auxinique. Les plants formés ont donc déjà commencé leur croissance, ce qui assure leur survie.

La rhizogène semble, en l'absence de traitement auxinique, plus active dans la partie apicalc des rameaux.

(2) Même milieu de base, dont les macroéléments sont dilués au cinquième. Régulateur de croissance : AIB : $5.10^{-6} \mathrm{M}$. 
La production de plants a été assurée par des pieds-mères en serre et en pépinière (de un à trois ans), en plusieurs vagues de bouturage durant le printemps et l'été.

\section{Conclusion}

Culture in vitro et bouturage herbacé ont permis en 1980-1981 la production de plus de deux mille plants, nécessaires à l'installation de collections, de parcs à pieds-mères de boutures (herbacées ou de racines) et des premières plantations comparatives qui seront constituées en 1982 dans le Centre, le Nord et l'Est de la France. Le bouturage herbacé donne de bons résultats, tout en nécessitant des conditions moins sophistiquées que la culture in vitro; c'est sans doute pour l'instant la technique la plus facilement applicable au stade commercial. 